\title{
Engaging Creative Media Students' Motivation: The Influence of Autonomy, Peer Relationships, and Opportunities in the Industry
}

\author{
Jae Eun Oh ${ }^{1, *}$, Jeffrey C. F. Ho ${ }^{1}$, Chris Shaw ${ }^{2} \&$ Justin Chan $^{1}$ \\ ${ }^{1}$ School of Design, The Hong Kong Polytechnic University, Kowloon, Hong Kong \\ ${ }^{2}$ School of Puttnam School of Film \& Animation, LASALLE College of the Arts, Singapore \\ *Correspondence: School of Design, The Hong Kong Polytechnic University, Kowloon, Hong Kong. E-mail: \\ jae.oh@polyu.edu.hk
}

Received: September 18, 2018

Accepted: October 15, 2018 Online Published: December 7, 2018

doi:10.5430/wje.v8n6p1

URL: https://doi.org/10.5430/wje.v8n6p1

\begin{abstract}
Motivating students in creative media courses can be a challenge due to the demand for creativity which is hard to be taught. Hence, motivation needs to be re-identified and re-addressed for the creative disciplines. Conventionally, creative media courses adopt the studio-based learning, and with this unique dynamic teaching approach, students are required to have face-to-face tutorial sessions with their tutors on a regular basis, as well as participate in group projects and produce creative artefacts of industry standard quality. In this paper, we investigate the critical motivators for creative media students and identify those factors throughout the study. The study aims to examine how crucial and influential the autonomy, peer relationship and the future career opportunities for students' motivation. Research includes a survey with questions based on a conceptual framework adopted from self-determination theory. The results suggest that autonomy, peer relationships and the opportunity for future careers are the primary motivators for students in the programme. The implications of the findings are discussed, and recommendations are provided to faculty members in the creative programmes.
\end{abstract}

Keywords: motivation, autonomy, peer relationships, industry relations, creative media course

\section{Introduction}

In the educational sector, motivation has been emphasized as a key component for student learning. Educators have consistently examined how to motivate students and prevent them from becoming demotivated and disinterested in their learning (Pintrich \& Zusho 2007). Commonly, students in creative media courses are in a discipline where they must constantly produce creative artefacts such as animation or live-action films. Feldman (2003) addressed that 'sustained focus, hard work, well-organized knowledge, persistence in the face of failure, and a coherent presentation of the work' are required for creative work $(2003,220)$. Therefore, students need to fully engage in their learning, stay motivated and be creative to prevent themselves from becoming demotivated and losing interest in their creative pursuits. According to Amabile (1998), when students, in general, are intrinsically motivated, they tend to engage in their studies and projects for the challenge and enjoyment of it, and when creative media students are motivated, their level of performance improves. A number of scholars have identified various attributes to enhance learning motivation in different areas and settings, such as teacher-student interpersonal relationships (Christophel 1990; Burleson \& Samter 1990; Frymier \& Houser 2000; Shen et al. 2006; Thijs \& Verkuyten 2009; Rodriguez-Keyes et al. 2013; Oh 2018); using social media to improve the learning experience (Collins \& Halverson 2010; Wodzicki, Schwämmlein \& Moskaliuk 2012; Tarantino et al. 2013; Celik et al. 2014); and adopting project-based learning to emphasize the construction of students' learning experience (Kolb 1984; Blumenfeld et al. 1991; Thomas 2000; Mazer et al. 2007; Ma 2016). However, the topic of motivating students in creative media education has not been sufficiently or substantially covered in existing research. So far, only few scholars have applied self-determination theory (SDT) to the student motivation in the creative discipline settings. Oh (2018) has studied the SDT framework that utilized to the creative classroom, and it has shown that the SDT model is valuable regarding motivating, specifically intrinsic motivation, creative media students. Creative media programs are unique with different types of teaching approaches such as studio-based learning and project-based learning that students need to engage with their 
project fully. The key concepts of motivation in SDT are competence, autonomy, and relatedness and it needs to be identified and explored how these elements can be applied and helped to the creative media students' motivation.

Thus, in this paper, we will investigate and examine creative media students' motivation and motivating factors, as well as how students engage in the learning process with the support of SDT. In examining the expectations students hold toward their relationships with peers and future careers, we use SDT in this study to identify the impact of motivation on students' learning experience and position the current study in the literature.

This research also explores the influence of student motivation on their willingness for the choice of their future creative career. As the educators need to respond to the market for students' sustainable employability in the industry as a creative professional, it is important to understand student' motivation for their choice of future creative career. In order to succeed in these aims, the study needs to address the following research questions:

1. What are the motivational factors that affect creative media student initiatives in their learning?

2. How does the industry relation influence the student motivation in their learning?

3. How does peer relationship motivate students?

\section{Literature Review}

\subsection{Creative media students' motivation}

Unlike other disciplines, creative media students are taught in a studio-based learning approach, engaging in face-to-face tutorials, critique reviews and sharing sessions (Oh 2018) throughout the academic year. The advantage to studio-based learning is making students engage in their studies and take ownership of their work (Ma 2016) by having constant interaction with their teachers and peers in allocated space, the studio. These advantages help students to remain motivated while they work on their projects (Oh 2018). Flink, Boggiano, and Barrett (1990) write that student autonomy, actively supported by teachers in learning, can direct a student's higher motivation, curiosity and desire to accept challenges. Ma (2016) comments that students benefit from close teacher-student and peer-peer relationships found in studio-based learning and from positive interpersonal relationships in general. Mazer et al. (2007) suggest that offering opportunities to cultivate the student-teacher relationship can ultimately create a positive learning experience for both parties. These factors affect a certain level of the learning experience and influence students' motivation to learn.

According to Oh (2018), creative media students have already demonstrated high motivation before and after joining the course. Since they all strive for artistic goals, findings show that these students are intrinsically motivated rather than driven by external rewards like exam scores or the financial security of their future career. However, many students mentioned during the interviews that they were concerned about their career prospects after graduation (Oh 2018).

\subsection{Autonomy}

Dalton and Crosby (2008) write that balancing challenge and physical support are critical to students' learning and development. Optimal levels of challenge help to enhance motivation. Autonomy is considered important among creative media students in this research because of the uniqueness of teaching approaches in creative media programs which are project-based and studio-based learning. Students feel more engaged and motivated when they perceive that they own their projects and thus become independent learners. An effective teaching approach for creative media students is necessary to obtain this goal. For example, studio-based learning is traditionally adopted to the curriculum so students may engage in studio tutorials, critiques and sharing sessions in the designated space (Oh 2018). Ma (2016) states that this approach provides students with the advantage of higher engagement and learning autonomy, while Flink, Boggiano, and Barrett (1990) add that these benefits enhance student motivation and the willingness to accept challenges. The close relationship between teachers and students is another important factor that affects the students' quality of learning (Christophel, 1990) and autonomy; it has definite positive effects if students feel fully supported and trust that their teachers are giving them ownership of the learning process. Deci and Ryan (2016) posited students' autonomous motivation can display positive educational outcomes. Also, the autonomy support by teachers for students' autonomous motivation has been emphasized (Ulstad et al, 2018; Ryan \& Deci, 2016). Whether teachers shape a relatable learning environment and what teaching approaches they adopt as their pedagogy are essential to student motivation.

\subsection{Peer Influence}

Generally, teaching approaches commonly adopted by creative media courses provide opportunities to foster an 
environment driven by close interpersonal relationships. As students spend time on their project in the studio, they build up a rapport with their classmates; therefore, peer influence is crucial in the studio-based learning setting. In addition, since students must complete many group projects during their course of study, the peer effect should be taken seriously in terms of enhancing student motivation in creative media courses. Wentzel et al (2017) also postulate the positive support from peers motivate students and they become more engaging at school. Eisenkopf (2010) writes that in general, peers have an impact on each other's performance and motivation during the overall process of the academic learning cycle. For the most part, creative media students share new ideas, seek technical help and receive feedback and support from each other on their creative products. They eventually learn and teach each other through peer learning. Boud et al. (2001) define peer learning as a 'two-way reciprocal learning activity' $(2001,3)$ where learners can take part in their learning environment. This is especially true among creative media students, where peer learning is reinforced and has become the learning culture in studio-based settings. This culture is created by both students and educators, as it is efficient and beneficial for student engagement as well as creating a sense of belonging in their community. Students also feel encouraged to perform better in team projects, as they do not want to ruin their relationships with their peers.

As creative media students engage with their projects during the learning process, the performance of each student is affected by the behaviour and characteristics of their teammates (Eisenkopf, 2010). The overall effect of peer groups can motivate or demotivate students during their course of study, as they spend most of their time with each other in the studio where they learn and carry out their projects. Group projects and the collaborative learning experience encourage students to learn from others, allowing students to become more involved in cooperation and peer learning as they share their knowledge during feedback sessions (Keppel et al. 2006).

\subsection{Future Employability}

There has been a rapid growth in animation and media-related courses at tertiary institutions around the world, ranging from short courses designed to impart specific skills, to diplomas, B.A. degrees and postgraduate research degrees (Ward 2013, 335). Thus, job opportunities have become increasingly competitive. Creative media majors, like other art majors, plan for careers such as working at commercial studios, freelancing, entrepreneurship or self-employment (Miller et al. 2016). Therefore, students require long-term prospects for their employability, and connections with the industry are crucial.

To prepare for their future careers and promote themselves, students need to hone not only their technical skillset but also soft skills such as networking and bringing exposure to their work through social network sites, festivals or exhibitions (Oh 2015). Oh (2015) also writes that schools should be encouraged to provide potential platforms for mentorship and longstanding aspirations for students' future careers. The means for providing mentorship and long-term aspirations should be associated with industry professionals, for instance, workshops and guidance conducted by said professionals. Students can experience specific knowledge, skillsets, and inspiration for industry standards through these interactions. Conducting masterclasses, inviting guest speakers or hosting workshops with famous artists from the industry can help students to develop the mindset of entrepreneurship for their continuing career planning (Oh 2015). Wells and Arcadias (2007) emphasize that creative workers are needed to be more than just 'worker bees' as the industry grows $(2007,75)$.

\subsection{Theoretical Framework: Self-determination Theory (SDT)}

Self-determination theory (SDT) was developed by Deci and Ryan $(1985,2002)$. SDT focuses on both innate psychological needs and the external conditions that structure the foundation of people's self-motivation and personality integration (Deci \& Ryan 1985). They write that the more a person's need for competency (feeling competent with tasks and activities), relatedness (feeling included or affiliated with others) and autonomy (a sense of control and agency) (Chen, \& Jang 2010) are satisfied as basic, universal needs, the more intrinsically motivated that person will be in any given situation.

The researchers adopted the SDT because it is applicable and appropriate for this study and developed the framework shown in the table below. The conceptual framework in the table was previously applied to the usage of social media with SDT and has been modified for this study. The column under 'expected motivational aspects for the phenomenon of students' intrinsic motivation' suggests the adopted conceptual framework from SDT. 
Table 1. Conceptual Framework (Oh, 2018)

\begin{tabular}{ll}
\hline Motivational factors under SDT & $\begin{array}{l}\text { Expected motivational aspects for the phenomenon of students' intrinsic } \\
\text { motivation }\end{array}$ \\
\hline $\begin{array}{l}\text { Competence } \\
\text { - Learners experience an effective } \\
\text { interaction }\end{array}$ & - Students feel they learn ample knowledge and information from the \\
& - Students feel that they know how to use their specific domain knowledge \\
& - Students want to challenge their limits to pursue higher technical and \\
& aesthetic goals \\
Relatedness & - Students feel involved when they work as a group \\
- Learners feel connected and a & - Students perceive their peers as one of the most critical factors in their \\
sense of belonging to the & projects and school life \\
community & - Students feel a connection with the industry through networking with \\
& professionals \\
& - Students perceive opportunities for their future career as they get exposed \\
more frequently & - Students feel supported when receiving encouragement \\
& - Students become more eager and dedicated when given freedom over \\
their project and maintain ownership of their learning \\
- Learners feel supported and \\
become a source of action
\end{tabular}

Using this conceptual framework, the next section will examine the competence, relatedness, and autonomy that motivate creative media students, as well as the influence of SDT factors.

\section{Method}

This study used questionnaires to amplify the validity of the data gained. A survey was conducted to obtain credible information. The survey questions were based on the theoretical framework adopted from SDT (Deci \& Ryan 1985).

We administered a voluntary survey to 115 students enrolled in four film and animation undergraduate programmes. To obtain a representative sample, we included students from two universities in two Asian metropolises, one in Hong Kong $(n=31)$ and one in Singapore $(n=84)$. The questionnaire consisted of 38 questions on a 5-point Likert scale. The questions concerned different aspects of motivation and areas of possible influence: competency, attitude towards the learning environment, perceived quality of instructors' effort, attitude towards group-based learning and expectations towards their programme and career. The questionnaire also included open-ended questions regarding these aspects to allow respondents to express their perceptions in their own words. The questions are presented in Appendix A. A hyperlink to the online version of the questionnaire was distributed over social media to the students' mid-semester.

\section{Result}

\subsection{Respondents}

115 students filled in the questionnaire. The majority of respondents comprised year two and year three students (Table 2).

Table 2. The Composition of the Student Sample

\begin{tabular}{llll}
\hline Programmes & Year 1 & Year 2 & Year 3 \\
\hline Diploma in Animation & 0 & 22 & 14 \\
Diploma in Broadcast Media & 0 & 2 & 3 \\
B.A. in Animation Arts & 6 & 17 & 19 \\
B.A. in Digital Media & 16 & 15 & 0 \\
\hline
\end{tabular}




\subsection{Quantitative Data}

To examine the mediating effects of motivation at the subject level, mediation models were tested using Hayes's (2017) PROCESS macro on SPSS (Model 4), with 10,000 bootstraps resampled at bias-corrected and accelerated 95\% confidence intervals.

Results indicated that students' degree of autonomy in each programme indirectly influenced their motivation to pursue a creative career via its effects on motivation at the subject level. The indirect effect was significant: $\mathrm{B}=.12$, $\mathrm{SE}=.06, \mathrm{LLCI}=.01, \mathrm{ULCI}=.26$.

Mediation analysis on the indirect effect of student competency through motivation at the subject level to the effects of motivation at the career level did not show the indirect effect to be significant: $\mathrm{B}=-.05$, SE $=.05$, LLCI $=-.15$, $\mathrm{ULCI}=.03$.

Mediation analysis on the indirect effect of students' attitudes towards their group-based learning experience through motivation at the subject level to motivation at the career level was significant: $\mathrm{B}=.18, \mathrm{SE}=.06, \mathrm{LLCI}=.09$, ULCI $=.32$. This indicates that students' attitudes toward their group-based learning experience indirectly influences their motivation to pursue a career in the creative industry via the effects on motivation at the subject level.

Mediation analysis on the indirect effect of students' perceived sufficiency of opportunities to prepare themselves for future employment through motivation at the subject level to motivation at the career level was significant: $\mathrm{B}=.12$, $\mathrm{SE}=.04, \mathrm{LLCI}=.04, \mathrm{ULCI}=.21$. This indicates that students' perceived sufficiency of opportunities to prepare themselves for future employment indirectly influences their motivation to pursue a career in the creative industry via its effects on motivation at the subject level. In other words, an abundance of opportunities to build relationship with the creative industry can motivate students in their studies and such influence can indirectly motivate them to choose relevant careers in the creative industry.

\subsection{Qualitative data: Overall}

We analysed student responses to the open question about what they feel motivates them at the programme level. We placed more focus on the answers related to student autonomy at the programme level, student-student relationships or group-based learning and opportunities to prepare for and relating to the industry. To illustrate the emergent themes in the qualitative data collected in the open questions, we used word cloud analysis (Cidell 2010) using the online tool (https://tagcrowd.com/). This revealed emergent themes in the word cloud: 'projects', 'students', 'work', and 'industry' (Fig. 1).

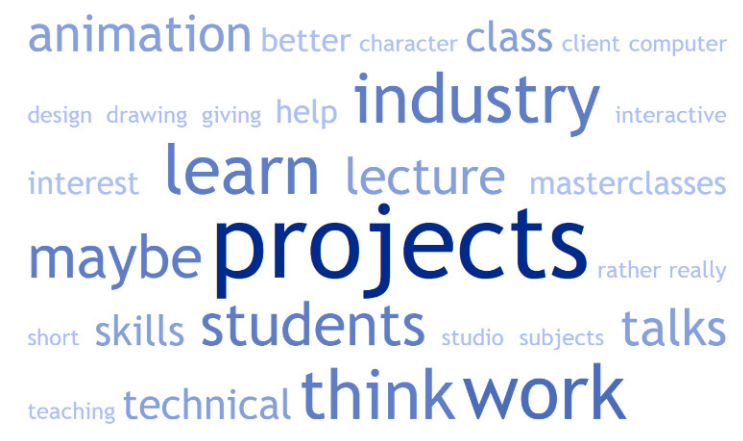

Figure 1. Word Cloud Analysis of Student Responses to the Open Question about What to Add to Their Programme to Increase Their Motivation

\subsection{Autonomy}

Regarding autonomy, students expressed a desire to have more control of their projects in terms of equipment and logistics. Students stated that the equipment they are allowed to use for their projects motivates them. The respondents also gave details regarding the computer resources they use for their projects. Specifically, they demanded remote access to these computer resources. Remote access provides students with the flexibility to determine when to work on their projects.

Another group of autonomy motivators that emerged in the student responses was control over group management. 
They stated that the authority to choose their own team motivates them in the programme.

P7: 'Grouping that can [be] chose[n] by ourselves.'

P17: “...can find our groupmate[s] by our self.'

\subsection{Relatedness among Students}

The respondents expressed motivators related to relatedness or relationships between students. Although each individual is in charge of their own interpersonal relationships, respondents expressed desire for support that a programme or a school might offer. Consider these quotes:

P23: 'Not too sure about that. Just a way to create good relations with teammates..? Maybe in terms of team building games or activities... or sports even. Maybe even lunch together or pizza in a class where we have to stay in the ccs room and chat or have some activities together even just for an hour or so where everyone participates with forfeits and whatnot.'

P33: 'More group-involved projects. Animation always involves a team, and I want to learn [...] how to handle more different types of people.'

The respondents suggested activities and measures that can support students in building relationships with one another and enhance their collaboration skills.

\subsection{Relatedness with the Industry}

The respondents suggested several different ways to enhance their relatedness with or readiness to join the industry. One type of measure involves projects with real clients in the industry.

P16: 'More project[s] like the Co-op project or maybe [an] internship.'

P35: 'When I was in poly, we were given a lot of client projects even in the first year. Although it was VERY terrifying, tough and stressful, it was definitely more fun and learning became much faster. Currently, in school, it is all project and homework based. Gets very boring and feels like learning is very stagnant. Having client projects not only helped my learning, but it also made me gr[o]w as a person and as a group member. I feel that it will help to push the motivations of all the students to see the work created by their classmates and getting constructive feedback [...] from lecturers and clients alike.'

These quotes demonstrate that projects involving clients, while stressful, can motivate students.

Another means of relatedness is through engagement with the industry or practitioners. This engagement can take the form of career talks or project collaboration. The forms of engagement suggested by students include masterclasses with industry professionals, industry/career talks, projects inside the industry and internships.

\section{Findings and Discussion}

In summary, Motivation at the subject level is necessary, as the results suggest that autonomy and relatedness not only affect student motivation in the classroom but can indirectly affect their motivation to choose a career in a relevant creative industry. In this section, we highlight and discuss each key finding.

Key Finding 1 - Sense of autonomy indirectly affects the motivation of having a relevant career, via its effects on motivation in the programme

Creative and design education often involve project-based work. By working on and completing projects, students can learn and grow in their progress. Our findings highlight one critical element in project-based learning, which is autonomy. Project-based learning hands over the responsibilities for projects to the students. In a project-based learning setting, many students prefer more control and autonomy to their projects. As shown in our results, autonomy over their own projects can be a motivator in classrooms. As shown in our results, autonomy over their own projects can be a motivator in classrooms. Students want to have more control over their projects in terms of their ways of completing their projects (e.g., control of computing resources and team management).

It implies that educators can consider giving students more power when they are given more responsibilities for their learning in project-based contexts. More power given to the students potentially suggests more freedom for the students as well. In turn, this may encourage students to do well in their projects. While our current study did not cover this area, future research could investigate the consequences and influence of the enhancement of student autonomy regarding responsibilities, freedom, and performance. 
Key Finding 2 - Peer relationships indirectly affects the motivation of having a relevant career, via its effects on motivation in the programme

Studio-based education is another common approach in creative and design education. There are extensive projects involving group work in typical design education. Within an emphasis on project-based learning, the studio becomes a space for students to discuss, collaborate and work on their projects. The studio is like a second home for them. This explains why the student respondents in our study expressed that supporting their peer relationships is an important motivator. Bonding between students is essential for effective group work. The challenge for educators is what exactly to offer in support of students' peer relationships in order to enhance these bonds. Future studies could examine different methods of supporting these peer relationships. The motivating effects of other closely related aspects of relatedness between students, such as the sense of belonging and bonding, should also be investigated in the future.

Key Finding 3 - Relationships with the industries indirectly affects the motivation of having a relevant career, via its effects on motivation in the programme

One significant insight from the current study is that student motivation is not only about performance and achievement while at school but is also influential in their career choices. This suggests that industry professionals should also be concerned about motivating students at the school to ensure the health of the creative industry. Our findings indicate that students are willing to be exposed to relevant creative industries, and that this kind of exposure can be a motivator for students. One possible means, according to our research, is engaging students with industry professionals at school through methods such as masterclasses and career talks. Student respondents revealed that these could be motivators for them. Future studies could take a closer look at the motivating effects of different forms of engagement with industry professionals. Examples of involvement include industry talks (e.g., on the latest opportunities, technologies, and trends), masterclasses and internships.

\subsection{Key Insights for Educators}

The results suggest that motivating students in their programmes matters more than their engagement at the programme level. Students' motivation in their studies can affect their future career choices. Three approaches to motivation suggested by our respondents are giving students control of their projects, supporting them to maintain peer relationships, and providing them to build relationships with the creative industries. An important insight for educators is that motivators at school might influence not only students' studies but also their future career choices.

\subsection{What about Competency?}

In our study, no significant effects of competency were found. One possible reason is that the question we asked about competency focused on the respondents' recently completed projects. This focus might not sufficiently capture students' perception about their competency in their studies in general. Future studies should ask questions that capture respondents' motivation in a more general sense.

\section{Conclusion}

This study investigated how SDT, competence, relatedness, and autonomy can influence and enhance creative media students' motivation, and it also gives insights on how SDT can be applied to the creative education setting. Throughout the study, researchers observed that students in creative media courses are primarily concerned with three aspects: 1) independent learning, wherein they have control over their learning process with their project; 2) peer relationships, as rapport with their peers is crucial given that students spend most of their time at the studio; and 3) industry relations, as students consider the network building with the industry professional is critical for job-seeking after graduation. However, the competency aspect of SDT was not emphasized in the findings. For students, they consider autonomy and relatedness, rather than competence, to be the primary motivational attributes for their learning experience in the classroom setting.

Indeed, students require guidance and support from teachers who can provide a positive impact through the mentorship (Hill \& Rowe 1996). A creative teaching style and support are essential for educators to harbour a positive atmosphere (Oh 2018) during the academic years; consequently, students become more confident as they gain full control over their projects. Furthermore, teacher encouragement can reinforce and strengthen students' sense of belonging to the community of practice and their sense of relatedness with the industry.

Findings show that relatedness is one of the primary motivators among creative discipline students. Two specific kinds of relatedness are essential in this setting of creative education which is peer relationship and industry 
engagement. From the open-ended questionnaires in the survey, students displayed the considerable importance of the peer effect. Due to the nature of their studies, they must continually collaborate with each other as groupmates. Hence, rapport and affinity among themselves become critical factors in their motivation. Conversely, students feel demotivated when problems arise among team members (Oh 2018).

Industry prospects is another of the students' key concerns. Thus, educators must understand the students' needs and nurture them to develop the right perspective for seeking relevant and sustainable careers (Oh 2015). By shaping and guiding the students toward a constructive and long-term relationship with the industry, educators ensure students will stay motivated toward the expectation of a future profession. Promoting or bringing exposure to students' creative projects and conducting networking sessions with industry professionals can be remarkably advantageous for their future careers.

Studies on motivating creative media students have not yet been fully explored, and the topic deserves more research attention. The findings and suggestions in this research work to contribute to creating knowledge with the hopes of inspiring faculty members in the field who aim to foster their students' motivation and nurture them to become lifelong learners. Cultivating a culture of independent learning for students to enjoy their experience, promoting collaborative projects among students to encourage peer learning and support as well as providing opportunities for contact with the industry will be the crucial components to maintain students' intrinsic motivation.

\section{References}

Amabile, T. M. (1998). How to kill creativity. Harvard Business Review, 76(5), 76-87.

Blumenfeld, P., Soloway, E., Marx, R., Krajcik J., Guzdial, M., \& Palincsar, A. (1991). Motivating project-based learning: Sustaining the doing, supporting the learning. Educational Psychologist, 26(3/4), 369-398. https://doi.org/10.1080/00461520.1991.9653139

Boud, D., Cohen, R., \& Sampson, J. (2001). Peer learning and assessment. In D. Boud, R. Cohen \& J. Sampson (Eds.), Peer Learning in Higher Education. London, Kogan Page, pp. 67-81.

Burleson, B. R., \& Samter, W. (1990). Effects of cognitive complexity on the perceived importance of communication skills in friends. Communication Research, 17, 165-182. https://doi.org/10.1177/009365090017002002

Celik, I., Goknur K. A., \& Tayfun, C. O. (2014). Social media for academics: Motivation killer or booster? Advanced Learning Technologies (ICALT), IEEE $14^{\text {th }}$ International Conference.

Chen, K. C., \& Jang, S. J. (2010). Motivation in online learning: Testing a model of self-determination theory, Computers in Human Behavior, 26, 741-752. https://doi.org/10.1016/j.chb.2010.01.011

Christophel, D. M. (1990). The relationship among teacher immediacy behaviors, student motivation, and learning. Communication Education, 39, 323-340. https://doi.org/10.1080/03634529009378813

Cidell, J. (2010). Content clouds as exploratory qualitative data analysis. Area, 42(4), 514-523. https://doi.org/10.1111/j.1475-4762.2010.00952.x

Collins, A., \& Halverson, R. (2010). The second educational revolution: Rethinking education in the age of technology, Journal of Computer Assisted Learning, 26(1), 18-27. https://doi.org/10.1111/j.1365-2729.2009.00339.x

Deci, E. L., \& Ryan, R. M. (1985). Intrinsic Motivation and Self-Determination in Human Behavior. New York: Plenum. https://doi.org/10.1007/978-1-4899-2271-7

Deci, E. L., \& Ryan, R. M. (1991). A motivational approach to self: Integration in personality. In R. Dienstbier (Ed.), Nebraska Symposium on Motivation: Perspectives on Motivation (Vol. 38). Lincoln: University of Nebraska Press, pp. 237-288.

Deci, E. L., \& Ryan, R. M. (2002). Handbook of Self-Determination Research. Rochester, NY: University of Rochester Press.

Deci, E. L., \& Ryan, R. M. (2016). Optimizing Students' Motivation in the Era of Testing and Pressure: A Self-Determination Theory Perspective. In: Liu W., Wang J., Ryan R. (eds.), Building Autonomous Learners. Springer, Singapore, pp. 9-29. https://doi.org/10.1007/978-981-287-630-0_2

Eisenkopf, G. (2010). Peer effects, motivation, and learning. Economics of Education Review, 29(3), 364-374. 
https://doi.org/10.1016/j.econedurev.2009.08.005

Feldman, D. H. (2003). Key issues in creativity and development. In R. K. Sawyer, V. John-Steiner, S. Moran, R. J. Sternberg, D. H. Feldman, J. Nakamura, et al., (Eds.), Creativity and development. New York: Oxford University Press, pp. 219-220.

Frymier, A. B., \& Houser, M. L. (2000). The teacher-student relationship as an interpersonal relationship. Communication Education, 49(3), 207-219. https://doi.org/10.1080/03634520009379209

Hayes, A. F. (2017). Introduction to Mediation, Moderation, and Conditional Process Analysis: A Regression-Based Approach (2nd ed.). The Guilford Press.

Hill, P., \& Rowe, K. (1996). Multilevel modeling in school effectiveness research. School Effectiveness and School Improvement, 7, 1-34. https://doi.org/10.1080/0924345960070101

Keppell, M., Au, E., Ma, A., \& Chan, C. (2006). Peer learning and learning-oriented assessment in technology-enhanced environments. Assessment \& Evaluation in Higher Education, 31(4), 453-364. https://doi.org/10.1080/02602930600679159

Kolb, D. A. (1984). Experiential Learning: Experience as the Source of Learning and Development. Prentice Hall.

Ma, H. (2016). A study of blended learning strategies for project-based studies. Asia Pacific Journal of Contemporary Education and Communication Technology, 2(1), 50-57.

Mazer, J. P., Murphy, R. E., \& Simonds, C. J. (2007). I'll see you on "Facebook": The effect of computer mediated teacher self-disclosure on student motivation, affective learning and classroom climate. Communication Education, 56(1), 1-17. https://doi.org/10.1080/03634520601009710

Miller, A. L., Dumford, A. D., Gaskill, S., Houghton, R., \& Tepper, S. J. (2016). To be or not to be (an arts major): Career aspirations and perceived skills of graduating seniors across multiple disciplines. SNAAP Special Report for the National Endowment for the Arts. Bloomington, IN: Center for Postsecondary Research, Indiana University, School of Education. Retrieved from https://www.arts.gov/sites/default/files/ResearchArt-Works-Indiana.pdf

Oh, J. E. (2015). Nurturing aspiring young artists for the animation and VFX industry: A Singapore perspective. DesignEd Asia Conference 2015 Retrieved from http://designedasia.com/Full_Papers/2015/B4_Nurturing\%20Aspiring\%20Young\%20Artist.pdf

Oh, J. E. (2018). Educators and Social media: Learning Motivators in Creative Media Courses. Asia Pacific Journal of Contemporary Education and Communication Technology, 4(1), 130-138. https://doi.org/10.25275/apjcectv4i1edu15

Pintrich P. R., \& Zusho A. (2007). Student motivation and self-regulated learning in the college classroom. In R. P. Perry \& J. C. Smart (Eds.), The Scholarship of Teaching and Learning in Higher Education: An Evidence-Based Perspective. Springer, Dordrecht.

Rodriguez-Keyes, E., Schneider, D. A., \& Keenan, E. K. (2013). Being known in undergraduate social work education: The role of instructors in fostering student engagement and motivation. Social Work Education, 32(6), 785-799.

Shen, D., Laffey, J., Lin, Y., \& Huang, X. (2006). Social influence for perceived usefulness and ease of use of course delivery system. Journal of Interactive Online Learning, 5(3), 270-282.

Tarantino, K., \& McDonough, J. (2014). Effects of student engagement with social media on student learning, $A$ Review of Literature (online). Retrieved 15 June 2014 from http://student affairs.com/ejournal/Summer

Thomas, J. W. (2000). A Review of Research on Project-Based Learning. Retrieved from http://www.autodesk.com/foundation

Thijs, J., \& Verkuyten, M. (2009). Students' anticipated situational engagement: The roles of teacher behavior, personal engagement, and gender, The Journal of Genetic Psychology, 170(3), 268-286.

Ulstad, S. O., Halvari, H., \& Deci, E. L. (2018). The role of students' and teachers' ratings of autonomous motivation in a self-determination theory model predicting participation in physical education. Scandinavian journal of educational research. https://doi.org/10.1080/00313831.2018.1476917

Ward, P. (2013). Animation studies as an interdisciplinary teaching field. In S Buchan (Ed.), Pervasive Animation. KY: Routledge/Taylor \& Francis, pp. 327-335. 
Wells, B., \& Arcadias, L. (2007). Issues in animation education. Animation Journal, 15, 63-80.

Wentzel, K. R., Muenks, K., McNeish, D., \& Russell, S. (2017). Peer and teacher supports in relation to motivation and effort: A multi-level study. Contemporary Educational Psychology, 49, 32-45

Wodzicki, K., Schwämmlein, E., \& Moskaliuk, J. (2012). Actually, I wanted to learn”: Study-related knowledge exchange on social networking sites. Internet and Higher Education, 15(1), 9-14.

\section{Appendix A}

This appendix presents the questions that comprised the questionnaire used in this study. Content in parentheses represents annotations explaining the purpose of the questions. These annotations are for clarification and did not appear on the original questionnaire.

Questions used in the questionnaire

How do you perceive your ability to guide and direct your learning in the programme?

(Autonomy in the programme)

Generally speaking, how do you perceive the last project you completed?

(Competency regarding the project)

How do you perceive the LEARNING EXPERIENCE of working in GROUPS?

(Attitude towards learning in groups / Relatedness among students)

Do you feel you are given sufficient OPPORTUNITIES to prepare yourself for future EMPLOYMENT?

(Perceived sufficiency of opportunities to prepare themselves for future employment / Relatedness with the industry)

How would you describe your OVERALL level of MOTIVATION to the SUBJECT you are STUDYING?

(Motivation towards the subject)

How would you describe your OVERALL level of MOTIVATION to the CAREER you are following?

(Motivation towards future career)

In order to increase your MOTIVATION, what would you like MORE of in your programme?

(An open question about motivators in the programme) 